\title{
BMJ Open Targeted social care for highly vulnerable pregnant women: protocol of the Mothers of Rotterdam cohort study
}

\author{
Marije van der Hulst, ${ }^{1}$ Marjolein W de Groot, ${ }^{1}$ Johanna P de Graaf, ${ }^{1}$ Rianne Kok, ${ }^{2}$ \\ Peter Prinzie, ${ }^{2}$ Alex Burdorf, ${ }^{3}$ Loes C M Bertens, ${ }^{1}$ Eric A P Steegers ${ }^{1}$
}

To cite: van der Hulst M, de Groot MW, de Graaf JP, et al. Targeted social care for highly vulnerable pregnant women: protocol of the Mothers of Rotterdam cohort study. BMJ Open 2018;8:e020199. doi:10.1136/ bmjopen-2017-020199

- Prepublication history and additional material for this paper are available online. To view these files, please visit the journal online (http://dx.doi. org/10.1136/bmjopen-2017020199).

Received 20 0ctober 2017 Revised 2 January 2018 Accepted 15 January 2018

Check for updates

${ }^{1}$ Department of Obstetrics and Gynaecology, Erasmus MC, University Medical Centre Rotterdam, Rotterdam, The Netherlands

${ }^{2}$ Department of Psychology, Education and Child Studies, Erasmus University, Rotterdam, The Netherlands

${ }^{3}$ Department of Public Health, Erasmus MC, University Medical Centre, Rotterdam, The Netherlands

Correspondence to

Marije van der Hulst

m.vanderhulst@erasmusmc.n

\section{ABSTRACT}

Introduction Social vulnerability is known to be related to ill health. When a pregnant woman is socially vulnerable, the ill health does not only affect herself, but also the health and development of her (unborn) child. To optimise care for highly vulnerable pregnant women, in Rotterdam, a holistic programme was developed in close collaboration between the university hospital, the local government and a non-profit organisation. This programme aims to organise social and medical care from pregnancy until the second birthday of the child, while targeting adult and child issues simultaneously. In 2014, a pilot in the municipality of Rotterdam demonstrated the significance of this holistic approach for highly vulnerable pregnant women. In the 'Mothers of Rotterdam' study, we aim to prospectively evaluate the effectiveness of the holistic approach, referred to as targeted social care.

Methods and analysis The Mothers of Rotterdam study is a pragmatic prospective cohort study planning to include 1200 highly vulnerable pregnant women for the comparison between targeted social care and care as usual. Effectiveness will be compared on the following outcomes: (1) child development (does the child show adaptive development at year 1?) and (2) maternal mental health (is maternal distress reduced at the end of the social care programme?). Propensity scores will be used to correct for baseline differences between both social care programmes.

Ethics and dissemination The prospective cohort study was approved by the Erasmus Medical Centre Ethics Committee (ref. no. MEC-2016-012) and the first results of the study are expected to be available in the second half of 2019 through publication in peer-reviewed international journals.

Trial registration number NTR6271; Pre-results.

\section{INTRODUCTION}

There is an abundance of evidence that low socioeconomic status (SES) is related to decreased (mental) health of the individual. ${ }^{1-3}$ Exposure to determinants such as low income, unemployment, being a single parent and living in a deprived neighbourhood increases levels of chronic stress, which in turn results in a decreased health status of the individual. ${ }^{14}$ Also, persons who chronically experience stress might be left with diminishing overall resources to adequately

\section{Strengths and limitations of this study}

- Societal valorisation of knowledge through valuable collaboration between academics, government and a non-profit organisation to support the healthy development of future generations.

- The ecologically valid study design allows for results directly generalisable to the actual population, but increases risks of true effects being masked by unmeasured confounders.

- Comparison of two types of social care on multiple domains (maternal-specific and child-specific outcomes), collected through a multimethod approach: questionnaires, developmental and cognitive tasks and video and photo observations in the home environment.

- Unique insights into a notoriously difficult-to-reach population of highly vulnerable pregnant women, their problems and potential care pathways for these problems.

- The findings of our study are likely to be generalisable to other contexts and countries, since vulnerable pregnant women are present in all countries and improvement of care for these women may contribute to better outcome measures.

cope with stressful situations, which often results in a downward spiral of more unhealthy and unfavourable behaviour. ${ }^{1} 2$ 4-9 Moreover, these negative effects do not only affect the individual, but also the persons who are closely related to them and even the next generation. ${ }^{310-16}$ Decreased self-sufficiency and increased levels of chronic stress may negatively influence competent parenting and a healthy parent-child relationship. ${ }^{18}$ Also, prenatal exposure to stress can have detrimental effects on the (unborn) child: including, but not limited to, being born small for gestational age, developing obesity and behavioural problems in early childhood and later in life. ${ }^{10-1619-29}$

In general, care for people with problems related to low SES is the responsibility of the social care system. In the Netherlands, social 
care is usually carried out by a community social care team: a multidisciplinary team of professionals located in the neighbourhood of their clients. ${ }^{30}$ Based on the needs of the client, care is either focused on adult issues (such as financial problems or unemployment) or problems regarding children and adolescents (such as underperformance and skipping school). This strict separation of the social care in adult and child care seems logical, but is in most cases not optimal, since impact of risk and adversity is not limited to one generation and can simultaneously affect both parent(s) and child(ren).

Within Rotterdam, $57 \%$ of the children grow up in a neighbourhood with low SES, and within the Netherlands, it has the highest percentage of children growing up in poverty $(25 \%)$, in a family living on welfare $(19 \%)$, with a low parental level of education $(20 \%)$ and with one or both parents being unemployed (10\%) ${ }^{31-36}$ Moreover, in the period of 2009-2014, perinatal mortality and morbidity within the municipality of Rotterdam (8.9 and 173.4 per 1000 deliveries, respectively) was higher than the national promillage ( 7.8 and 141.7 per 1000 deliveries respectively). ${ }^{36-40}$ Within the municipality of Rotterdam, the Erasmus Medical Centre, the local government and a non-profit organisation are combining their expertise to support the healthy development of future generations. By improving the psychosocial situation of highly vulnerable pregnant women, these stakeholders aim to support a healthy development of the (unborn) child. Recently, a holistic approach was developed to integrate medical and social care for highly vulnerable pregnant women and their (unborn) children, as well as targeting adult and child issues simultaneously. ${ }^{41}$ A pilot study of this holistic approach ( $\mathrm{n}=281$ pregnant women) in 2014 highlighted the magnitude of the problem within Rotterdam, as well as the accumulation of problems experienced by these women (see table 1). The programme was considered promising to optimise care for these highly vulnerable women, but yet awaits empirical testing of its effectiveness.

With the 'Mothers of Rotterdam' (MoR) study, we will prospectively evaluate the effectiveness of this targeted social care on two domains: (1) child development; and (2) maternal mental health.

\section{METHODS}

The MoR study consists of a pragmatic prospective cohort designed to evaluate the effectiveness of targeted social care (TSC) for highly vulnerable pregnant women in Rotterdam. TSC is a selective prevention programme aimed at improving developmental opportunities for children from highly vulnerable pregnant women. TSC will be compared with care as usual for this high-risk population.

\section{Targeted social care}

The TSC programme has been developed in close collaboration between the university hospital, the local government and a non-profit organisation, and is carried out by one of the social care providers within the municipality of Rotterdam.
Table 1 Descriptive characteristics of pilot period for Targeted Social Care (TSC), based on self-report $(n=281)$

\begin{tabular}{|c|c|c|}
\hline & Categories & Amount \\
\hline \multirow[t]{6}{*}{$\begin{array}{l}\text { Age } \\
\text { Missing (9.6 \%) }\end{array}$} & $\begin{array}{l}\text { Adolescent } 15- \\
19 \text { years }\end{array}$ & $19(7.5 \%)$ \\
\hline & $\begin{array}{l}\text { Young adult } 20- \\
25 \text { years }\end{array}$ & $84(33.1 \%)$ \\
\hline & Adult 26-30 years & $72(28.3 \%)$ \\
\hline & Adult $31-35$ years & $50(19.7 \%)$ \\
\hline & Adult $36-40$ years & $19(7.5 \%)$ \\
\hline & Adult $>40$ years & $10(3.9 \%)$ \\
\hline \multirow[t]{3}{*}{ Parity } & Nullipara & $77(29.4 \%)$ \\
\hline & Primipara & $91(34.7 \%)$ \\
\hline & $\begin{array}{l}\text { Multipara (2-6 } \\
\text { children) }\end{array}$ & $94(35.9 \%)$ \\
\hline \multirow{3}{*}{$\begin{array}{l}\text { Sufficient income } \\
\text { Missing (47.7\%) }\end{array}$} & Sufficient income & $24(16.3 \%)$ \\
\hline & $\begin{array}{l}\text { Partly sufficient } \\
\text { income }\end{array}$ & $46(31.3 \%)$ \\
\hline & Insufficient income & $77(52.4)$ \\
\hline \multirow{2}{*}{$\begin{array}{l}\text { Debt } \\
\text { Missing (24.2\%) }\end{array}$} & Yes & $171(80.3 \%)$ \\
\hline & No & $42(19.7 \%)$ \\
\hline \multirow[t]{5}{*}{$\begin{array}{l}\text { Living conditions } \\
\text { Missing (16.4\%) }\end{array}$} & $\begin{array}{l}\text { Independent } \\
\text { housing }\end{array}$ & $142(60.4 \%)$ \\
\hline & Institution & $10(4.3 \%)$ \\
\hline & $\begin{array}{l}\text { No personal } \\
\text { residence }\end{array}$ & $75(26.7 \%)$ \\
\hline & Homeless & $5(2.1 \%)$ \\
\hline & Other & $3(1.3 \%)$ \\
\hline \multirow{3}{*}{$\begin{array}{l}\text { Imminent eviction } \\
\text { Missing (30.6\%) }\end{array}$} & Yes & $33(16.9 \%)$ \\
\hline & No & $161(82.6 \%)$ \\
\hline & Not applicable & $1(0.5 \%)$ \\
\hline \multirow[t]{4}{*}{$\begin{array}{l}\text { Educational level } \\
\text { Missing (50.9\%) }\end{array}$} & $\begin{array}{l}\text { No/only primary } \\
\text { education }\end{array}$ & $12(8.8 \%)$ \\
\hline & $\begin{array}{l}\text { Secondary general } \\
\text { education }\end{array}$ & $34(24.6 \%)$ \\
\hline & $\begin{array}{l}\text { Vocational } \\
\text { education }\end{array}$ & $86(62.3 \%)$ \\
\hline & College, university & $6(4.3 \%)$ \\
\hline \multirow{2}{*}{$\begin{array}{l}\text { Deprived } \\
\text { neighbourhood } \\
\text { Missing (12.5\%) }\end{array}$} & Yes & $164(66.7 \%)$ \\
\hline & No & 82 (33.3\%) \\
\hline
\end{tabular}

TSC has been developed to exclusively suit the population of highly vulnerable pregnant women and their (unborn) children. The programme emphasises social care in the home environment and also encourages compliance to medical care. The programme promotes a healthy lifestyle, as well as regular visits to appropriate healthcare providers: general practitioner, midwife, gynaecologist or other medical specialists and preventive child healthcare physicians. By doing so, the programme aims to reduce avoidance of care and to promote preventive health behaviour. 
The programme consists of three specific stages: (1) reducing acute stress by taking over pressing actions from the mother; (2) creating a calm and more structured environment, in collaboration with the mother, to enable the development of a secure mother-child relationship and ensuring a healthy infant development; and (3) enhancing parenting skills and sensitivity of the mother, while also stimulating the mother's autonomy and encouraging her to actively participate in society.

The care is provided by a team of social care professionals and social work students (University of Applied Sciences, final year of their bachelor's degree). Quality of care is ensured by close supervision of the professionals with regard to the progress of the student, the mother and the social care programme. Improvement in the situation of the mother is evaluated in detail every 3 months, and care is handed over to the professional at any time, when necessary. The intensity of TSC is high at the start (two home visits a week during the first stage) and decreases over time until the second birthday of the child (one home visit every 2 weeks during the final stage).

\section{Care as usual}

The social care provided by the community social care team is characterised by a distinction between adult issues (such as financial problems or unemployment) and problems regarding children and adolescents (such as underperformance and skipping school). The care providers are trained in detecting (potential) problems while providing basic support and guidance for solving or reducing these problems. If necessary, the client is referred to other (social) care and welfare organisations for additional support. Care is of average intensity, with approximately one visit every (two) week (s), over a period between 3 and 9 months.

\section{Eligibility criteria and allocation}

Eligible participants are all pregnant women, residing in Rotterdam, who are classified as potentially highly vulnerable by their referring party. The referring party is most often an obstetric professional, but also social workers, the highly vulnerable pregnant woman herself or her social network, can refer to the programme. Women are categorised as potentially highly vulnerable when at least three are indicated within the following domains: pregnancy, residence, finance, occupation, parenting, health, social functioning and safety (see online supplementary appendix 1 ).

After referral, a home visit is planned to assess the number and intensity of the problems within the household. When a pregnant woman is indeed identified as highly vulnerable during the home visit (criteria summarised in table 2), she is allocated to either TSC or care as usual. For several postal codes care as usual is not available for this particular population. As a result, women are assigned to care as usual when it is available in their residential neighbourhood, and to TSC when it is not (see online supplementary appendix 2). Due to the pragmatic character of the study, blinding is not possible. However, risk of bias is reduced since both participants and care providers are unaware of the actions of the other social care programme. Furthermore, data will be processed by researchers blinded to the social care programme the mother was allocated to.

Although both programmes are allowed to collaborate with other (social) welfare organisations and professionals, participants are not allowed to be involved in both TSC and care as usual. Both social care programmes are voluntary and discontinued at the request of the mother.

\section{Participant timeline}

Pregnant women are informed about the study during the first home visit. Informed consent is obtained from the pregnant women, as well as for their (unborn) children. When fathers have acknowledged the child to be their own, informed consent from the father is required as well. To also include as many non-Dutch speaking participants as possible, all study materials are also available in English, Arabic, Polish, Turkish and Spanish.

Women who do not provide written consent or who are not proficient in one of the available languages are not able to participate in the study, while both social care programmes remain available to them. If a woman stops with the social care programme, participation in the study

Table 2 Eligibility, inclusion and exclusion criteria

\begin{tabular}{|c|c|c|}
\hline Eligibility criteria & Inclusion criteria & Exclusion criteria* \\
\hline $\begin{array}{l}\text { Women residing in the municipality of } \\
\text { Rotterdam } \\
\text { Women who are pregnant during } \\
\text { informed consent procedure } \\
\text { Women who are identified as highly } \\
\text { vulnerable by referring party: at least } \\
\text { three problems (from a total of } 46 \\
\text { problems) divided over at least two } \\
\text { different problem domains (eight in } \\
\text { total). } †\end{array}$ & $\begin{array}{l}\text { Women who are identified as highly } \\
\text { vulnerable during home visit: at least } \\
\text { three problems (from a total of } 46 \\
\text { problems) divided over at least two } \\
\text { different problem domains (eight in } \\
\text { total). } † \\
\text { Women who agreed to receive care from } \\
\text { either TSC or care as usual. }\end{array}$ & $\begin{array}{l}\text { Women who did not provide written } \\
\text { consent. } \\
\text { Women who were not sufficiently } \\
\text { skilled at understanding either: } \\
\text { - Dutch } \\
\text { - English } \\
\text { - Arabic } \\
\text { - Polish } \\
\text { - Spanish } \\
\text { - Turkish }\end{array}$ \\
\hline
\end{tabular}

*Teenage mothers and women with previous pregnancies are not excluded from the study.

†For a complete overview of the problems and the problem domains, see online supplementary appendix 1. 
will be continued with permission of the woman until her child is 2 years old. When a woman stops her participation in the study, social care will be continued until no longer deemed necessary.

Data will be prospectively collected at a maximum of nine different time points: (1) at inclusion; (2) 6 weeks after the start of social care, but before delivery; (3) 6 weeks postpartum; (4) 6 months postpartum; (5) 12 months postpartum; (6) 18 months postpartum; (7) 24 months postpartum; (8) at the end of social care; (9) and 6 months after ending social care. Time point 1 will not be available for all women, since it is possible that they have delivered their baby before meeting the criterion of receiving 6 weeks of social care. When the participant discontinues the social care programme prematurely, measurements from the last two time points are collected ( 8 and 9 ), and the research will continue regarding mother and child outcomes. Reasons for discontinuation are registered by their care provider. As acknowledgement for their contribution, and to encourage continuation in the study, participants are rewarded with a voucher worth $€ 10$, for participation at each time point.

To collect data on the well-being of the mother and her child, a multimethod approach is used to gather data: questionnaires, developmental and cognitive tasks and video and photo observations in the home environment. Data on medical and social care use are collected from the registries from social care professional(s); general practitioner(s); obstetric professional(s); the Preventive Child Health Centre, the Vaccination Office; and the Child Abuse/ Domestic Violence Agency. For a complete overview of the measurement points and measurement types, see online supplementary appendix 3 .

\section{Outcomes}

Primary outcomes of the study are child development and maternal mental health. Additionally, the process outcome of the study is received social care.

\section{Child development}

The proportion of children with a delay in overall development was measured at 1 year of age with the Ages and Stages Questionnaire (ASQ). ${ }^{42}{ }^{43}$ The ASQ will be completed by the mother and measures development in the following domains: communication, gross motor skills, fine motor skills, problem solving abilities and social interaction. ${ }^{42}{ }^{43}$ Delay is defined as below clinical cut-off for at least one of these domains. ${ }^{42} 43$

\section{Maternal mental health}

A reduction of stress, anxiety and/or depression within at least one category was measured with the Depression, Anxiety and Stress Scales. ${ }^{44} 45$ The difference between the scores at the start and at the end of social care will be used for primary analyses. ${ }^{46}$

\section{Process evaluation}

Self-sufficiency of the mother, as reported by her social care provider on the Self-Sufficiency Matrix $(\mathrm{SSM}),{ }^{47}$ is used to evaluate the received social care programmes.
The SSM is filled out by the social care provider at the start of the programme, every 6 months for the duration of either social care programme, at the end of the social care programme and after the 6-month follow-up period.

\section{Sample size calculation}

Sample size calculations were performed in G-power ${ }^{48}$ using a power of $80 \%$ and a type I error of 0.05 . We hypothesise that TSC will have more favourable results on both primary outcomes.

To test an expected difference between $12.5 \%$ of children with a developmental delay in the TSC programme and 20\% of children within care as usual, a total of 752 are needed (376 children per programme). For maternal mental health, 385 mothers per programme (770 in total) are needed to demonstrate a difference between $50 \%$ of mothers with improvement in TSC and $40 \%$ of mothers with improvement in care as usual. To account for dropout of participants, we aim to include 1200 highly vulnerable pregnant women within the study.

\section{Statistical methods}

Given the pragmatic design of this study, we will use analytical methods appropriate for quasi-experimental study designs, often used in evaluations of policy changes, which closely resembles our situation. Consequently, the analysis will only be performed per protocol. Also, since randomisation was not possible, propensity score matching will be used to correct for potential confounding due to allocation bias. The matched endpoints will be analysed using multivariable regression models. In these models, we will include potentially confounding determinants collected during the study, and outcomes from other domains.

Subgroup analyses will be performed, stratified by: ethnicity, parity, marital status, age of the mother and cognitive ability. These subgroup analyses will only be performed when large enough numbers are available (at least 20 observations in the smallest group). In case of missing data on potential confounders in the questionnaires, multiple imputation will be used, using Multivariate Imputation by Chained Equations (MICE) procedures and 10 imputed data sets. ${ }^{49}$ For the (photo and video) observations, imputation of missing variables will not be performed and missing data from the registries will be considered as 'not present'.

\section{Ethics and dissemination}

The study was approved in January 2016 (ref. no. MEC-2016012) and deemed compliant to the Dutch law on Medical Research on Humans. The study was registered in the Dutch Trial Registry (NTR6271). All data will be registered and analysed anonymously. Source documents and data will be preserved and stored for 15 years after study completion. The first results of the study are expected to be available in the second half of 2019 through publication in peer-reviewed international journals. 


\section{Declaration of interest}

Investigators confirm that there are no conflicts of interest for the overall trial.

\section{Trial status}

The MoR study started on 4 January 2016 and will be recruiting participants until 31 December 2019. The end date for data collection is 31 December 2020.

\section{Roles and responsibilities of coordinating centre}

The coordinating centre (Erasmus MC) will ensure adherence to Good Clinical Practice Guidelines in collecting, storing, and processing of data anonymously.

Acknowledgements We would like to thank both caregivers from TSC and care as usual for their cooperation to the study. Furthermore, we would like to thank all the participants who have thus far filled in the questionnaires and opened their home to us for several observations.

Contributors EAPS and JPG conceived the study. JPG, LCMB, MH and MWG initiated the study design. RK, PP, LCMB, AB and EAPS provided methodological expertise in the trial design. JPG is grant holder. MH and MWG implemented the trial design and will conduct primary statistical analyses and report results. All authors contributed to refinement of the study protocol and approved the final manuscript.

Funding This work was supported by 'De Verre Bergen Foundation', a philanthropic foundation that supports innovative ideas and research that have a positive impact on the municipality of Rotterdam.

Disclaimer The funder had no role in the design of this study, and will not have any role during its execution, analyses, interpretation of data or decision to submit results.

\section{Competing interests None declared.}

Patient consent Detail has been removed from this case description/these case descriptions to ensure anonymity. The editors and reviewers have seen the detailed information available and are satisfied that the information backs up the case the authors are making.

Ethics approval Research Ethics Committee of the Erasmus Medical Centre. Provenance and peer review Not commissioned; externally peer reviewed. Open Access This is an Open Access article distributed in accordance with the Creative Commons Attribution Non Commercial (CC BY-NC 4.0) license, which permits others to distribute, remix, adapt, build upon this work non-commercially, and license their derivative works on different terms, provided the original work is properly cited and the use is non-commercial. See: http://creativecommons.org/ licenses/by-nc/4.0/

(c) Article author(s) (or their employer(s) unless otherwise stated in the text of the article) 2018. All rights reserved. No commercial use is permitted unless otherwise expressly granted.

\section{REFERENCES}

1. Murali V, Oyebode F. Poverty, social inequality and mental health. Advances in Psychiatric Treatment 2004;10:216-24.

2. Najman JM, Clavarino A, McGee TR, et al. Timing and chronicity of family poverty and development of unhealthy behaviors in children: a longitudinal study. J Adolesc Health 2010;46:538-44.

3. Turner RJ, Wheaton B, Lloyd DA. The Epidemiology of Social Stress. Am Sociol Rev 1995:60:104-25.

4. Steptoe A, Feldman PJ. Neighborhood problems as sources of chronic stress: development of a measure of neighborhood problems, and associations with socioeconomic status and health. Ann Behav Med 2001;23:177-85.

5. Hankin J, McCaul ME, Pregnant HJ. alcohol-abusing women. Alcoholism: Clinical and Experimental Research 2000;24:1276-86.

6. Lumley J, Chamberlain C, Dowswell T, et al. Interventions for promoting smoking cessation during pregnancy. Cochrane Database Syst Rev 2009;3:CD001055.
7. Morland K, Wing S, Diez Roux A, et al. Neighborhood characteristics associated with the location of food stores and food service places. Am J Prev Med 2002;22:23-9.

8. Sampson RJ, Raudenbush SW, Earls F. Neighborhoods and violent crime: a multilevel study of collective efficacy. Science 1997;277:918-24.

9. Wen M, Browning CR, Cagney KA, et al. social capital and regular exercise during adulthood: A multilevel study in Chicago. Urban Studies 2007;44:2651-71.

10. Bergman K, Sarkar P, O'Connor TG, et al. Maternal stress during pregnancy predicts cognitive ability and fearfulness in infancy. $J$ Am Acad Child Adolesc Psychiatry 2007;46:1454-63.

11. Davis EP, Glynn LM, Dunkel Schetter C, et al. Corticotropin-releasing hormone during pregnancy is associated with infant temperament. Dev Neurosci 2005;27:299-305.

12. Davis EP, Glynn LM, Schetter CD, et al. Prenatal exposure to maternal depression and cortisol influences infant temperament. $J$ Am Acad Child Adolesc Psychiatry 2007;46:737-46.

13. de Weerth $C$, van Hees $Y$, Buitelaar JK. Prenatal maternal cortisol levels and infant behavior during the first 5 months. Early Hum Dev 2003;74:139-51.

14. Huizink AC, de Medina PG, Mulder EJ, et al. Psychological measures of prenatal stress as predictors of infant temperament. J Am Acad Child Adolesc Psychiatry 2002;41:1078-85.

15. Kinsella MT, Monk C. Impact of maternal stress, depression and anxiety on fetal neurobehavioral development. Clin Obstet Gynecol 2009;52:425-40.

16. Lou HC, Hansen D, Nordentoft M, et al. Prenatal stressors of human life affect fetal brain development. Dev Med Child Neurol 1994;36:826-32.

17. Belsky J. The determinants of parenting: a process model. Child Dev 1984:55:83-96

18. Brooks-Gunn J, Duncan GJ. The effects of poverty on children. Future Child 1997;7:55-71.

19. Davis EP, Snidman N, Wadhwa PD, et al. Prenatal maternal anxiety and depression predict negative behavioral reactivity in infancy. Infancy 2004;6:319-31.

20. Grant KA, McMahon C, Austin MP, et al. postnatal caregiving and infants' cortisol responses to the still-face procedure. Developmental Psychobiology 2009;51:625-37.

21. Hellemans KG, Sliwowska JH, Verma P, et al. Prenatal alcohol exposure: fetal programming and later life vulnerability to stress, depression and anxiety disorders. Neurosci Biobehav Rev 2010;34:791-807.

22. O'Connor TG, Heron J, Glover V. Alspac Study Team. Antenatal anxiety predicts child behavioral/emotional problems independently of postnatal depression. J Am Acad Child Adolesc Psychiatry 2002;41:1470-7.

23. Sood B, Delaney-Black V, Covington C, et al. Prenatal alcohol exposure and childhood behavior at age 6 to 7 years: I. doseresponse effect. Pediatrics 2001;108:e34.

24. Henderson J, Gray R, Brocklehurst P. Systematic review of effects of low-moderate prenatal alcohol exposure on pregnancy outcome. BJOG 2007;114:243-52.

25. Jaakkola JJ, Gissler M. Maternal smoking in pregnancy, fetal development, and childhood asthma. Am J Public Health 2004;94:136-40.

26. O'Leary CM, Nassar N, Kurinczuk JJ, et al. The effect of maternal alcohol consumption on fetal growth and preterm birth. BJOG 2009;116:390-400.

27. Toraño EG, García MG, Fernández-Morera JL, et al. The Impact of External Factors on the Epigenome. In:Utero and over Lifetime. BioMed research international, 2016.

28. Huang JS, Lee TA, Lu MC. Prenatal programming of childhood overweight and obesity. Matern Child Health J 2007;11:461-73.

29. Mattsson K, Källén K, Longnecker MP, et al. Maternal smoking during pregnancy and daughters' risk of gestational diabetes and obesity. Diabetologia 2013;56:1689-95.

30. Plexus K. Sociale wijkteams in ontwikkeling. Inrichting, aansturing en bekostiging (Municipal teams in development Organization, management and funding: KPMG Plexus, Amstelveen, 2013.

31. CBS. Meer dan 400 duizend kinderen met risico op armoede (More than 400.000 children with risk of poverty). 2017 https://www.cbs.nl/ nl-nl/nieuws/2016/19/meer-dan-400-duizend-kinderen-met-risicoop-armoede.

32. Rotterdam I. Armoede en schulden in Rotterdam: IDEM Rotterdam 2016 https://idemrotterdam.nl/wp-content/uploads/2016/12/ Feitenkaart-armoede-en-schulden-in-Rotterdam-webversie.pdf.

33. CBS. Aantal kinderen in bijstandsgezinnen groeit (Number of children in Welfare households is growing): Centraal Bureau voor de Statistiek (CBS). 2016 https://www.cbs.nl/nl-nl/nieuws/2016/34/aantalkinderen-in-bijstandsgezinnen-groeit. 
34. CBS. Aantal mensen dat bijstand ontvangt blijft stijgen (Number of individuals on welfare keeps rising): CBS. 2017 https://www.cbs.nl/ nl-nl/nieuws/2017/09/aantal-mensen-dat-bijstand-ontvangt-blijftstijgen.

35. CBS. Aandeel achterstandsleerlingen basisonderwijs afgenomen (Number of students in elementary school with parents of low educational level is decreasing). 2017 https://www.cbs.nl/nl-nl/n ieuws/2016/07/aandeel-achterstandsleerlingen-basisonderwijsafgenomen.

36. PRN. Perinatale Zorg in Nederland 2014: Perinatal Registry Netherlands. 2014 https://www.perined.nl.

37. de Graaf JP, Ravelli AC, de Haan MA, et al. Living in deprived urban districts increases perinatal health inequalities. J Matern Fetal Neonatal Med 2013;26:473-81.

38. de Graaf JP, Steegers EA, Bonsel GJ. Inequalities in perinatal and maternal health. Curr Opin Obstet Gynecol 2013;25:98-108.

39. Vos AA, Denktaș S, Borsboom GJ, et al. Differences in perinatal morbidity and mortality on the neighbourhood level in Dutch municipalities: a population based cohort study. BMC Pregnancy Childbirth 2015;15:201.

40. Vos AA, Posthumus AG, Bonsel GJ, et al. Deprived neighborhoods and adverse perinatal outcome: a systematic review and metaanalysis. Acta Obstet Gynecol Scand 2014;93:727-40.

41. Steegers EA, Barker ME, Steegers-Theunissen RP, et al. Societal valorisation of new knowledge to improve perinatal health: time to act. Paediatr Perinat Epidemiol 2016;30:201-4.

42. Squires J, Bricker D, Twombly E. Ages \& stages questionnaires. Baltimore, Maryland, 2009:257-182.

43. Squires J, Bricker D, Heo K, et al. Identification of social-emotional problems in young children using a parent-completed screening measure. Early Child Res Q 2001;16:405-19.

44. Ng F, Trauer T, Dodd S, et al. The validity of the 21-item version of the Depression Anxiety Stress Scales as a routine clinical outcome measure. Acta Neuropsychiatr 2007;19:304-10.

45. Norton PJ. Depression Anxiety and Stress Scales (DASS-21): psychometric analysis across four racial groups. Anxiety Stress Coping 2007;20:253-65.

46. Gomez F. A Guide to the Depression, Anxiety and Stress Scale (DASS 21). Central and Eastern Sydney primary health networks 2016 https://wwwcesphnorgau/images/mental_health/Frequently_Used/ Outcome_Tools/Dass21pdf.

47. Fassaert T, Lauriks S, van de Weerd S, et al. Psychometric properties of the Dutch version of the self-sufficiency matrix (SSM-D). Community Ment Health J 2014;50:583-90.

48. Faul F, Erdfelder E, Buchner A, et al. Statistical power analyses using $\mathrm{G}^{*}$ Power 3.1: tests for correlation and regression analyses. Behav Res Methods 2009;41:1149-60.

49. Buuren Svan, Groothuis-Oudshoorn K. mice : Multivariate Imputation by Chained Equations in R. J Stat Softw 2011;45. 